\title{
SAÚDE NA PERSPECTIVA DA GEOGRAFIA NOVA
}

\author{
Prof. Dr. Aldo Dantas \\ Pós-Graduação em Geografia da UFRN \\ Av. Senador Salgado Filho, 3000 - BR 101 Km, 92 - Lagoa Nova, CEP 59.078-970, Natal (RN), Brasil \\ Tel:(84)9193-6288-aldodantas@ufrnet.br \\ Pablo Ruyz Aranha \\ pabloruyz@gmail.com
}

\begin{abstract}
RESUMO
Este artigo adota a teoria da Geografia Nova na abordagem da saúde, pois entende que esta apresenta um arcabouço teórico-metodológico que possibilita a compreensão da saúde para além do setor saúde. A partir das categorias território usado, verticalidade e lugar são analisadas questões gerais sobre o sistema de saúde brasileiro e suas políticas de implantação de um modelo de assistência e prestação de serviços.
\end{abstract}

Palavras-Chave: Geografia Nova. Dinâmica dos lugares. Saúde. PACS-PSF/SUS.

\begin{abstract}
The theoretical and methodological framework of New Geography theory enables the understanding of health above the health sector. Then, this article adopts that theory in the health approach. General questions about the Brazil's health system and it politics of assitance and delivery model are analyzed by used territory, verticalities and place categories.
\end{abstract}

Key words: Geography. Places dinamic. Health. PACS-PSF/SUS.

\section{RÉSUMÉ}

Cet article adopte la théorie de la Géographie Nouvelle dans l'étude de la santé publique. On considère cette Géographie une possibilité que nous permts la compréhension de la santé au-delà d'une conception sectorielle. Des catégories d'analise geographique tel que le territoire usé, l'usage du territoire par les entreprises transnationales nomées dans la Geographie Nouvelle « verticalidade » et le lieu sont utilisées pour comprendre le système de la santé publique brésiliènne et ses politiques d'implantation d'un modèle d'assistence et offre des services dans ce domaine.

Mot Clés: géographie nouvelle. La dynamique des lieux. Usage du territoire, Santé publique PACS-PSF/SUS.

\section{Introdução}

Depois de algum tempo estudando o tema saúde chegamos à conclusão de que a Teoria da Geografia Nova é a melhor opção para uma análise geográfica da saúde na perspectiva que adotamos em nossas pesquisas, qual seja aquela de entender a saúde em sua complexidade. Assim pretendemos demonstrar que esta 'geografia renovada' contém um arcabouço teórico-conceitual que dá conta, de melhor explicar, a relação entre a saúde e a necessidade de entendê-la para além do setor saúde. Analisar a saúde do ponto de vista da Geografia Nova é entender a complexidade da constituição dos lugares e do direito ao entorno, é compreender a saúde do cidadão (constituída nos lugares) e não a saúde do indivíduo visto de forma isolada. Portanto, cidadania para geografia renovada diz respeito ao direito aos lugares, ao entorno.

Nesta perspectiva, acreditamos que as categorias de análise espacial miltoniana (espaço banal, território usado, paisagem, lugar, região, etc.), possibilitem explicar e fazer proposições, a partir de metodologias diferenciadas, na tentativa de contribuir para a melhoria da crise instalada no setor saúde brasileiro.

No livro "O Brasil: território e sociedade no início do século XXI" (2008), SANTOS e SILVEIRA operacionalizaram metodologicamente os usos do território brasileiro, também, a partir da variável saúde. Se referindo à saúde como um "consumo imaterial" os autores examinaram especificamente os "recursos da saúde" no Brasil, classificados e quantificados por tipologias de serviços. O encaminhamento de método proposto por SANTOS e SILVEIRA acreditamos ser o mais genuinamente geográfico para a questão, tendo na materialidade a base metodológica para o entendimento dos usos do território brasileiro pelos serviços de saúde. 
Este procedimento - a materialidade como condição para as ações - é originário da seguinte idéia: “[...] à ação humana como uma projeção da matéria” (SANTOS, 2006, p.93). Juntamos a isso a seguinte afirmação: “[...] a ação não se dá sem que haja um objeto, e, quando exercida acaba por se redefinir como ação e por redefinir o objeto (SANTOS, 2006, p.93).

Milton SANTOS considera que ao geógrafo cabe a responsabilidade de propor uma "visão totalizante do mundo", porém, partindo "[...] de sua própria província do saber, de um aspecto da realidade global" (SANTOS, 2006, p.114). No entanto, segundo SOUZA (2008, p.45), "muitos ainda utilizam o conceito geométrico de espaço e não o conceito geográfico de espaço, esta totalidade em movimento, esta instância social $[\ldots] "$.

Partindo da noção de espaço banal, "espaço de todas as pessoas, de todas as empresas e de todas as instituições, capaz de ser descrito como um sistema de objetos animado por um sistema de ações" (SANTOS, 2006, p.283), Milton Santos balizou a sua busca por "categorias analíticas simples que dêem conta da inseparabilidade do 'funcional' e do 'territorial'" (SANTOS, 2006, p.284). Assim, definiu o espaço geográfico como "um conjunto indissociável, solidário e também contraditório, de sistemas de objetos e sistemas de ações, não considerados isoladamente, mas como o quadro único no qual a história se dá" (SANTOS, 2006, p.63).

Segundo Milton SANTOS, “[...] o importante é realçar a inseparabilidade entre ação e objeto, para afirmar, [...] que o tema central da geografia não é separadamente os objetos, nem as ações, mas objetos e ações tomados em conjunto" (SANTOS, 2006, p.94). Nesta perspectiva, para Milton SANTOS “o objetivo da geografia moderna é da experiência técnica ou da utilização racional do espaço-tempo [...]; é uma geografia preocupada com todas as formas de existência" (SANTOS, 2006, p.48).

Portanto, a Geografia Nova ${ }^{1}$, apresenta um edifício teórico epistemológico consistente, atendendo as necessidades de operacionalização por nós demandadas. A análise geográfica da saúde por nós aqui proposta versa sobre uma das temáticas centrais da geografia renovada "[...] representada pela expressão anglo-saxônica place counts, isto é, o lugar tem importância" (SANTOS, 2006, p.19). No entanto, esta categoria analítica geográfica de natureza operacional, o lugar, é considerada de difícil tratamento empírico e teórico. Neste sentido Milton SANTOS adverte:

[...] o mais pequeno, isto é, o menor, é, na realidade, o mais difícil [de se estudar]. Porque qualquer fato e tudo o que se encontra no espaço total se explicam pelo movimento global da sociedade total - o Estado Nação, conjunto que se torna efetivo através de um elenco múltiplo de processos de várias ordens: social, econômica, política, cultural, ideológica. Tanto mais agente desce na escala geográfica e tanto maior é a seletividade e a expressividade das variáveis combinadas e assim o trabalho de achar a explicação é maior. Pois, cada lugar é o resultado da localização seletiva de uma combinação de fatores cuja explicação está num universo mais amplo, ou seja, no próprio universo, intermediado pelo Estado Nação. "O lugarzinho" não é pois o mais fácil, é o mais difícil (SANTOS, 1980, p.8) [Grifos Nossos].

\section{Questões gerais sobre a saúde no Brasil}

Mesmo atento ao conselho do mestre, de que o mais pequeno é o mais difícil, nós nos colocamos o desafio de tentar compreender o mais pequeno no intuito de mostrar a importância dos lugares (enquanto forma) como escala fundamental para se pensar a realização das normas e conseqüentemente para a realização das ações.

Entretanto lembramos que, o mesmo Milton SANTOS, nos chama a atenção para o fato de que nos dias atuais a densidade de relações, que fazem parte da dinâmica de um fenômeno, gera variáveis que se ligam a muitos objetos e a outros fenômenos, o que provoca a necessidade de estudos de generalizações que demandam análise nesta escala geográfica maior. É a partir destas generalizações que há a possibilidade de podermos, segundo SANTOS (1988, p.34), "voltar ao tema da geografia como "ciência dos lugares"”. 
Consideramos a tese intitulada Uso do Território Brasileiro e os Serviços de Saúde no Período Técnico-Científico-Informacional de Elisa ALMEIDA(2005) o trabalho de generalização mais denso que se utiliza do repertório teórico miltoniano no tratamento dos sistemas técnicos de saúde.

Neste trabalho a autora trata a questão dos serviços de saúde utilizando o território usado como categoria de análise principal, Elisa ALMEIDA(2005) faz uso da periodização como recurso de método na análise da sucessão dos sistemas técnicos de saúde no Brasil, sistematizando sua abordagem através das tipologias e topologias dos serviços.

Ao analisar de forma geral o Sistema de Saúde brasileiro Elisa ALMEIDA(2005, p.174-175) diz que o mesmo:

[...] está centrado no atendimento hospitalar. O modelo adotado, a partir de 1964, com a chegada dos militares ao poder deu prioridade à medicina privada voltada, mormente, para as ações curativas. $\mathrm{O}$ hospital tornou-se, neste modelo, um ícone de atendimento médico para o conjunto da população do país. Entre 1974 e 1980, as consultas hospitalares cresceram 220\% passando de 50 milhões para 160 milhões ao ano (Gazeta Mercantil: 31/03/1990). Os hospitais brasileiros, em sua grande maioria de natureza privada são vorazes consumidores de recursos públicos. Esses objetos técnicos-científicos são extremamente dispendiosos em virtude da constante incorporação tecnológica, da manutenção física dos estabelecimentos, e pela exigência de atualização constante de conhecimento e adoção de serviços especializados

Em alusão ao modelo assistencial da saúde adotado no Brasil, Elisa ALMEIDA (2005) ainda faz uma crítica importante:

o modelo pautado no hospital tem facilitado a entrada do grande capital nos serviços de saúde, dinamizando atividades correlatas ao seu crescimento, sem que haja necessariamente um compromisso com a realidade dos lugares (ALMEIDA, 2005, p.181).

Este indicativo dos problemas da saúde brasileira nos lugares relacionados ao modelo assistencial adotado no país é enfatizado pela autora:

A crise na saúde se instala nos lugares, sobretudo nas grandes cidades, em função do modelo privatista que se tornou hegemônico no território brasileiro. Enquanto as ações políticas não romper(e)m com esse modelo o SUS estará ameaçado, pois o mercado é cego em relação às necessidades das populações (ALMEIDA, 2005, p.182).

No entanto, Elisa ALMEIDA (2005, p.175) afirma que "desde a implantação do SUS, um dos objetivos é justamente a tentativa de se reverter esse quadro".

Ora, mas para haver esta reversão, uma política que visa atender à efetiva saúde dos indivíduos, dos cidadãos, precisa atentar e considerar os usos do território como abrigo, oposto a lógica do mercado que usa o território como recurso. Então, o que nos interessa discutir são os usos do território como abrigo pela categoria geográfica lugar, pois,

No lugar - um cotidiano compartido entre as mais diversas pessoas, firmas e instituições - cooperação e conflito são a base da vida em comum. Porque cada qual exerce uma ação própria, a vida social se individualiza; e porque a contigüidade é criadora de comunhão, a política se territorializa, com o confronto entre organização e espontaneidade (SANTOS, 2006, p.322).

Então, questionamos sobre qual a estratégia de organização que o Ministério da Saúde adotou para o SUS quanto à tentativa da 'reversão' do modelo de atenção à saúde dos cidadãos. Este processo é esboçado por TEXEIRA (2004):

Nos últimos 15 anos vem se desenvolvendo um complexo e heterogêneo processo de mudanças na 
gestão, no financiamento e na organização das unidades de prestação de serviços (postos e centros de saúde, ambulatórios, laboratórios e hospitais) em todo o país, ainda que em meio a uma série de difículdades de ordem política e financeira que podem ser notadas em acelerações e atrasos, algumas vezes mudanças de rumo e surgimento de novos obstáculos, tanto no nível federal quanto no estadual e no municipal. Além das preocupações com o financiamento e gestão, existe a preocupação com à construção de um novo modelo de atenção à saúde que concretiza os princípios do SUS, e fortaleça o "controle social" sobre a gestão do sistema (TEIXEIRA, 2004, p.20).

Muitos são os estudos que versam sobre o processo da Reforma Sanitária brasileira. Considerando este processo, evidenciamos a variável política como fundamento na constituição do que viria a ser o SUS. Assim, o movimento de descentralização ${ }^{2}$ das ações de saúde que se constituiu como um dos principais preceitos do SUS ganhou força na década de 1980 quando se iniciou "uma reação da sociedade contra a centralidade político-administrativa, econômica e fiscal nas mãos da União" (ALMEIDA, 2005, p.183).

Com o fortalecimento da instância municipal em decorrência da orientação política da descentralização como sinônimo de municipalização, se deflagrou uma preocupante repercussão no SUS sobre o entendimento muitas vezes de que as demandas municipais são locais. Contudo, compreendemos que as demandas do município não são as demandas locais! Não o local compreendido como lugar.

No entanto, o município enquanto território político, limitado por fronteiras, se caracteriza como um fato geopolítico que se exercendo enquanto norma torna-se uma variável imprescindível na medida em que adotamos o seguinte ponto de vista: "não se trata de partir de um [sub] espaço considerado em si cujos fenômenos se estudam, mas de fenômenos que criam os seus [sub] espaços" (SANTOS, 2006, p.105, nota 15).

O fenômeno o qual nos referimos - Programa de Saúde da Família (PSF) / Programa de Agentes Comunitários de Saúde (PACS) - é um programa de saúde inovador em nível local (no entendimento do Ministério da Saúde) que integra a organização institucional do SUS e atende a demanda estratégica para aquilo que TEIXEIRA (2004, p.20) considerou como "a preocupação com à construção de um novo modelo de atenção à saúde que concretiza os princípios [ou preceitos] do SUS". Além disso, esta estratégia organizacional corrobora com a tese da Elisa ALMEIDA(2005, p.191) de que "o SUS é uma verticalidade institucional que busca se contrapor ao forte acento privatizante que tem dominado a organização do sistema dos serviços de saúde brasileiro".

Politicamente, o PSF-PACS/SUS surge de um "programa 'vertical"” que seria implantado apenas nas regiões Norte e Nordeste do país (onde o objetivo era, em 1990, interromper a expansão da epidemia de cólera) passou a ser uma oportunidade de promover em larga escala uma mudança do modelo de atenção à saúde, a partir da redefinição do Programa de Agentes Comunitários de Saúde (PACS) e do seu sucessor, o Programa de Saúde da Família (PSF) (TEIXEIRA; SOLLA. 2005).

Historicamente, o PSF-PACS/SUS teve seus princípios associados progressivamente aos da medicina comunitária, o objeto de trabalho foi ampliado dos indivíduos à família, incorporando diretrizes além da clínica, adotando a epidemiologia, a administração e o planejamento em saúde como fundamentos de um modelo de atenção pautado pela

organização sistêmica dos serviços (complementaridade e hierarquização), pelo caráter multiprofissional das equipes de trabalho, pela utilização das informações epidemiológicas para o planejamento e a programação das ações de saúde e pela busca de integralidade das práticas (promoção, proteção e recuperação (TEIXEIRA; SOLLA. 2005, p.463). 


\section{PACS-PSF: um evento geográfico}

Enquanto fenômeno que cria subespaços, o PACS-PSF/SUS se constitui como um evento, que segundo Milton SANTOS (2006, p.94) "é um feixe de vetores, conduzido por um processo, levando uma nova função ao meio preexistente". Este meio preexistente é formado pelos lugares que, por sua vez, servem como "[...] aparatos de base das funcionalizações que as relações sociais vão exigindo pelo uso do território" (SOUZA, 2008, p.45). No entanto, como lembra Milton SANTOS (2006, p.94) “[...] o evento só é identificável quando ele é percebido, isto é, quando se perfaz e se completa. E o evento somente se completa quando integrado no meio. Somente aí há evento, não antes". Neste sentido, o PSFPACS/SUS enquanto evento integrado no meio, na perspectiva do lugar, se constitui como um meio funcional.

O PSF-PACS é uma proposta singular oriunda do movimento de medicina familiar dos Estados Unidos formatado em meados da década de 1960. Este movimento foi difundido para vários países da América Latina, sendo incorporado no Brasil nas instituições de ensino que serviu, posteriormente, de fundamentação para a política de organização da Atenção Básica brasileira, contribuindo institucionalmente na reorganização da prática médica e clínica (TEIXEIRA; SOLLA. 2005). Do ponto de vista teórico por nós aqui defendido este movimento diz respeito ao mundo como norma, ou seja, entre a universalidade e a individualidade instalam-se situações intermediárias. "O universal é o mundo como norma, uma situação não-espacial, mas que cria e recria espaços locais; o particular é dado pelo país, isto é, o território normado; e o individual é o lugar, o território como [forma]" (SANTOS, 2006, p.338).

A 'relação regulatória lugar-mundo' não se dá diretamente, esta relação é mediada pelo particular, o território nacional, que no caso brasileiro esta particularidade tem como fundamentação o Território Normado regido pela Constituição Federal de 1988, a qual inclui em sua segunda sessão o tema 'saúde' definindo-o, no artigo 196 como:

[...] direito de todos e dever do Estado, garantido mediante políticas sociais e econômicas que visem à redução do risco de doença e de outros agravos e ao acesso universal e igualitário às ações e serviços para sua promoção, proteção e recuperação.

A partir do instituído no artigo supracitado a operacionalização do SUS foi formatada através da criação das Normas Operacionais: NOB/91; NOB/93; NOB/96; NOAS/2001; NOAS 01/2002. A principal característica das Normas Operacionais é o seu poder regulatório na organização dos serviços e práticas de saúde que, por sua vez, por meio desse instrumental regulamentou o processo de descentralização, direcionando as especificidades das atribuições para cada ente federativo.

Destacamos a primeira NOB editada em 1991 (NOB/91) que fortaleceu os municípios, habilitados pelo SUS, na gestão direta dos serviços de saúde. Para melhor compreender esta norma, se faz necessário considerar o contexto político de sua implementação, distinguindo primeiramente, o "clima político" entre a institucionalização e a implantação do SUS .

Todavia chamamos a atenção para o fato de que a municipalização está diretamente ligada aos princípios gerais da política do Ministério da Saúde que é pensada de forma vertical e setorial, excluindo assim um pressuposto fundamental da teoria da Geografia Nova qual seja aquele da diferenciação das partes no interior do todo e da diferenciação dos lugares no conjunto do espaço. Desta forma entendemos que a política de saúde no Brasil aliena-se da idéia de território usado e de lugar, deformando a prática da descentralização, o que leva a não garantia da plena autonomia dos municípios, uma vez que a autonomia depende do tipo de gestão à qual estão vinculados.

Outro elemento que consideramos importante para a análise aqui desenvolvida nos é dado pela definição de cidade entendida como "o concreto, o conjunto de redes, [a] materialidade visível do urbano" (SOUZA, 1997, p.9), uma vez que nossa proposta de análise tem a materialidade como condição para as ações. 
Além disso, consideramos também a cidade como um dos lócus privilegiados dos sistemas técnicos. SANTOS e SILVEIRA (2008, p.20) consideram que "esses sistemas técnicos ${ }^{5}$ incluem, de um lado, a materialidade e, de outro, seus modos de organização e regulação". É por isso que Maria Laura SILVEIRA (2000) propõe que "as técnicas não podem ser interpretadas apenas como materialidade, mas devem ser vistas, também, como formas de organização". E daí, indicar como princípio o seguinte encaminhamento metodológico: "é preciso indagar, ao mesmo tempo, a natureza material e normativa dos sistemas técnicos, sua localização e sua intencionalidade" (SILVEIRA, 2000, p.213).

A partir deste encaminhamento se faz necessário discutir os 'princípios explícitos' e as 'normas criadas intencionalmente', as quais, segundo Milton SANTOS (2006, p.228), "a vida social é organizada em derredor", pois, a mediação das normas na organização do território ${ }^{6}$ é imprescindível para a compreensão do encontro entre os dois sistemismos ${ }^{7}$ do espaço geográfico.

O principal instrumento normativo que regula o PSF-PACS/SUS é a Política Nacional de Atenção Básica à Saúde aprovada pela Portaria nº 648/GM de 28 de março de 2006, que estabelece a revisão de diretrizes e normas para a organização da Atenção Básica, para o Programa Saúde da Família (PSF) e para o Programa Agentes Comunitários de Saúde (PACS). Essa Política defende a idéia de que os municípios são os protagonistas do processo de descentralização, tendo a Saúde da Família como estratégia prioritária para a organização do setor saúde.

No entanto o que conseguimos verificar na prática é que estas políticas fazem com que os municípios cumpram metas e normas universais que na maioria das vezes estão em descompasso com a singularidade dos lugares.

\section{Considerações Finais}

Consideramos que na cidade há milhares de lugares, e que a cidade se vivifica pela dinâmica destes lugares (SOUZA, 2008), então, o que nos interessa discutir são os lugares da cidade.

Esta perspectiva inspira o nosso principal questionamento: há uma congruência entre a intencionalidade normativa (das Políticas de saúde) e a constituição da materialidade dos lugares (bases da funcionalização e materialização destas políticas)?

Ora, os preceitos constitucionais do SUS, não podem ser analisados sem considerarmos o condicionamento do espaço geográfico que tem na sua materialidade um componente imprescindível para sua explicação, "que é, ao mesmo tempo, uma condição para a ação; uma estrutura de controle, um limite à ação; um convite à ação" (SANTOS, 2006, p.321). É com esta proposta que convidamos os colegas geógrafos e profissionais da saúde para um debate onde os elementos espaciais sejam levados em consideração, pois além dos indivíduos, o território e o lugar são reveladores "das geografias da desigualdade".

\section{Notas}

\footnotetext{
1 "O que propomos é uma geografia preocupada com um espaço aberto a todos, isto é, um espaço que não seja um instrumento de exploração dos homens e que não os separe. Essa geografia nova se impõe no mundo de hoje. E em países como o Brasil ela deve estar em relação íntima com a manutenção da integralidade nacional e a reconstrução do país, considerando o espaço como um todo concreto das relações internacionais e das relações internas. Se atingirmos a compreensão da sociedade como um todo, do espaço como uma instância dentro da sociedade total e de como há uma relação entre espaço e sociedade, poderemos atingir, quem sabe, essa geografia mais comprometida" (SANTOS, 1980, p.12).
}

\footnotetext{
2 "A descentralização política era defendida pelos representantes locais - governadores e prefeitos que argumentavam serem reféns durante o regime militar dos casuísmos e clientelismos do governo federal. A descentralização administrativa permitiria que estados e municípios assumissem responsabilidades nas execuções das políticas públicas e atendessem as necessidades das populações no que se refere à saúde, educação, saneamento, habitação, entre outras" (ALMEIDA, 2005, p.185-186). "Na saúde a bandeira da descentralização é encampada, na segunda metade da década de 1980, por membros da burocracia estatal, que naquele momento ocupavam cargos de comando no INAMPS. Este grupo vinha debatendo desde a década de 1970, a necessidade urgente de uma reforma sanitária no país que rompesse com a dicotomia existente nos serviços de saúde. Havia uma reação à acentuada centralização
} 
das ações de saúde que marcaram o período militar, tendo como conseqüências à segmentação no atendimento. Desse modo, as ações coletivas eram de competência do Ministério e as individuais ficaram sob responsabilidade do Ministério da Previdência e Assistência Social que estruturou, majoritariamente, uma rede de serviços privados remunerados com recursos públicos. O êxito por esse grupo que ocupava o INAMPS está consagrada na Constituição de 1988, quando a saúde é reconhecida como direito de cidadania e como dever do Estado" (ALMEIDA, 2005, p.186-187). "Todavia, [...], o processo de construção do SUS ocorreu num clima político e econômico distinto daquele de sua criação na Constituição de 1988, já sob os ventos do Neoliberalismo, no decorrer da década de 1990" (ALMEIDA, 2005, p.188). "A perspectiva de descentralização neoliberal, amplamente defendida pelos organismos internacionais [...] está associada à privatização com a redução do papel do Estado na economia, que deve se submeter às leis do mercado. A minimização do papel do Estado se faria concomitantemente ao processo de descentralização, com a transferência de responsabilidades para instancias locais, mais próximas das necessidades da população e, portanto, consideradas nesta visão, mais confiáveis para evitar os desperdícios de recursos disponíveis e, mais aptos a realizar mudanças que repercutissem numa melhoria das condições de vida das populações desses países" (ALMEIDA, 2005, p.188).

\begin{abstract}
3 “A eleição de Fernando Collor de Mello (1989), para presidente da república, coincide com o afastamento no INAMPS do grupo vinculado aos ideais da VIII Conferência de Saúde, passando o comando para o grupo conservador que buscou manter as estruturas e funções do antigo sistema. Neste contexto é que surge o conceito de municípios e estados habilitados pelo SUS editada na primeira NOB de 1991 (NOB/91), que estariam comprometidos com a gestão direta dos serviços de saúde. Previa a formação de um fundo setorial de saúde e o funcionamento de conselhos comunitários. Essa norma incentivou os convênios de municipalização, habilitando os municípios a receber os repasses dos recursos para o pagamento dos serviços diretamente com o Ministério da Saúde, retirando da cena o Estado [federado] como mediador entre os poderes federais e municipais, que foi um dos princípios básicos do SUDS que antecedeu o SUS. Isso implicou no fortalecimento dos laços políticos entre o governo federal e os municípios, ampliando, dessa maneira a base de sustentação política do presidente Fernando Collor. Desse modo, é que a descentralização dos serviços de saúde se tornou quase sinônimo de municipalização" (ALMEIDA, 2006, p.191-192).
\end{abstract}

${ }^{4}$ A atual política de saúde do MS impõe aos municípios brasileiros dois tipos de gestão: Gestão Plena de Atenção Básica e Gestão Plena de Sistema. Para nós isso implica numa verticalidade institucional (universal) que condiciona as ações locais.

5 “Já que a técnica é também social, pode-se lembrar que sistemas de objetos e sistemas de ações em conjunto constituem sistemas técnicos, cuja sucessão nos dá a história do espaço geográfico" (SANTOS, 2006, p.332) [Grifos Nossos].

${ }^{6}$ A organização do território é oriunda da idéia de organização do espaço e "diz respeito a normas que refuncionalizam as atividades sem que ocorra a produção de obras de engenharia"(CATAIA, 2001, p.195).

7 "O espaço é, hoje, o teatro do encontro de dois sistemismos: o sistemismo dos objetos impele ao sistemismo das ações e o condiciona. [...] O fato de o sistemismo dos objetos condicionar o sistemismo das ações não significa que entre eles haja uma relação automática. Existem mediações, e, entre elas, a lei, as normas [...]” (SANTOS, 2006, p.227-228).

\title{
Referência Bibliográfica
}

ALMEIDA, Eliza Pinto de. Uso do território brasileiro e os serviços de saúde no período técnicocientífico-informacional. São Paulo. 2005. Tese de Doutorado, Faculdade de Filosofia Ciências e Letras FFLCH/USP.

CATAIA, Márcio Antônio. Território nacional e fronteiras internas: a fragmentação do território brasileiro. São Paulo. 2005. Tese de Doutorado, Faculdade de Filosofia Ciências e Letras - FFLCH/USP.

SANTOS, Milton. Responsabilidade social do geógrafo. Recife: Boletim recifense de geografia - ano 1 $-\mathrm{n}^{\mathrm{o}} 1-$ jan/mar. 1980.

Metamorfoses do espaço habitado. São Paulo: Editora Hucitec, 2008.

. A natureza do espaço: tempo e técnica, razão e emoção. São Paulo: EdUSP, 2006. 384 p.

SANTOS, Milton e SILVEIRA, Maria Laura. O Brasil: Território e sociedade no início do século XXI. São Paulo: Editora Record. 2001.

SILVEIRA, Maria Laura. Indagando as técnicas... um caminho para entender o território. In SANTOS, Ney de Maria; SILVA, Maria Auxiliadora de e LAGE, Creuza Santos (Org.). Os lugares do mundo. A globalização dos lugares. Salvador: UFBA. DGE. Mestrado em Geografia, 2000.

SOUZA, Maria Adélia Aparecida de. Cidade: lugar e geografia da existência. In SILVA, Sylvio Bandeira de Melo e VASCONCELOS, Pedro de Almeida (Org.). Novos estudos de geografia urbana. Salvador: Ed. da Universidade Federal da Bahia, 1999. p. 09-18.

. A metrópole e o futuro: a dinâmica dos lugares e o período popular da história. In SOUZA, Maria Adélia Aparecida de (Org.). A metrópole e o futuro: refletindo sobre campinas. Campinas: edições territorial, 2008.

TEIXEIRA, Carmen Fontes. O SUS e a vigilância em saúde. Rio de Janeiro: FIOCRUZ/EPSJV/ 
PROFORMAR, 2004.

TEIXEIRA, Carmen Fontes e SOLLA, Jorge Pereira. Modelo de atenção à saúde no SUS: trajetórias do debate conceitual, situação atual, desafios e prespectivas. In LIMA, Nísia Trindade (Orgs.). Saúde e democracia: história e perspectivas do SUS. Rio de Janeiro: Editora FIOCRUZ, 2005.

Trabalho enviado em agosto de 2009

Trabalho aceito em setembro de 2009 